\title{
Bilingualism in the scientific and educational discourse of China: psychophysiological, organizational and pedagogical aspects
}

\author{
Besarion Meskhi ${ }^{1}$, Pavel Ermakov ${ }^{2}$, Svetlana Ponomareva ${ }^{1}$, and Olga Fedotova ${ }^{1, *}$ \\ ${ }^{1}$ Don State Technical University, 344003, 1 Gagarin sq., Rostov on Don, Russia \\ ${ }^{2}$ Southern Federal University, 344006, B. Sadovaya Str., 105/42, Rostov on Don, Russia
}

\begin{abstract}
The article analyzes certain aspects of the representation of modern scientific, educational and organizational discourse, characterizing the state of research in the field of theory and practice of bilingualism. It is emphasized that the problem of cultivating bilingualism has acquired particular relevance in modern China, which pursues a policy of active use of national languages in regions and administrative units inhabited by representatives of other, non-Han, ethnic groups. Based on the content analysis, the activity of foreign researchers of the problems of bilingualism and trilingualism in China has been established. Three thematic clusters are identified and characterized, within which modern research is carried out and the policy of bilingualism in China is implemented.
\end{abstract}

\section{Introduction}

The modern world is influenced by two opposite trends. On the one hand, it is characterized by the expansion of global ties, which requires possession of new means of communication, knowledge of foreign languages, as well as ethno-confessional characteristics of representatives of other cultures. On the other hand, there is a tendency to preserve ethnocultural specificity, which is embodied in the language as the bearer of national mentality and cultural traditions. [1- 3]. Due to the most diverse geopolitical and geocultural processes, the borders of many states have changed, they included new territories. Most modern states are multi-ethnic or multinational states. They are historically inhabited by representatives of different religions, confessions, worldviews; the interest in the study of which has been carried out for a long time [4-5] and persists at the present time.

One of the countries that play a significant role in the cultural, political and economic life of the modern world is China, which is a multinational country. Currently, representatives of many ethnic groups, scripts and languages live in China: there are officially 56 ethnic groups.

Thus, the linguistic picture of China is very complex and multifaceted. Language requirements are regulated by law.

\footnotetext{
*Corresponding author: fod1953@yandex.ru
} 
In China, Article 37 of the Constitution of the People's Republic of China guarantees the equality of nationalities and their languages; Article 47 of the Constitution imputes to the administrations of autonomous regions the knowledge and use of the local language of an ethnic group.

Ethnic minorities, which make up about $13 \%$ of the country's population, must learn to speak and to write in the standard national language (Standard Mandarin). Research of biand polynigvigm issues is carried out within the framework of the implementation of the State Program for the Implementation of Regional Autonomy of Ethnic Minorities. Improving the system of language education is considered as a factor in preserving national identity, health and development of the entire nation. Considering the need to preserve and develop a common communication space within the country and the need to implement communication links on the external circuit of the country, researchers are actively addressing various aspects of the problem of polylingualism in China. The cultural diversity of this country is of particular interest both as a historical phenomenon and as a large-scale research ground.

\section{Methodology}

The purpose of the study is to determine the main directions of research on the problems of multilingualism and bilingualism in China in the scientific and educational discourse.

The empirical source - research on the problems of poly- and bilingualism, the results of which are presented in the form of scientific publications in top-rated journals included in the Internet search platform Web for Science.

Research methods - content analysis, interpretation, the comparative analysis, generalization, classification, cluster method.

When carrying out content analysis, the conceptual category of analysis was the category of "polylingualism", presented in any semantic variants. The unit of account is a publication indexed in a journal included in the "Web of Science" list.

For graphic design of the results the EXCEL program was used.

The research was carried out in two steps.

\section{Results}

The first stage of the study was devoted to the detection and definition of the dynamics of the emergence and country belonging of studies on the problem of poly-liguism in China in chronological order.

On the basis of a content-analytical study on the search attribute "polylingualism / multylinguaim" (in its semantic variants reflecting bilingualism and trilingualism), it was established that there are 19 thematic publications presented in the Web of Science resource. The polygon of their distributions in the chronology of publications is shown in Figure 1. 


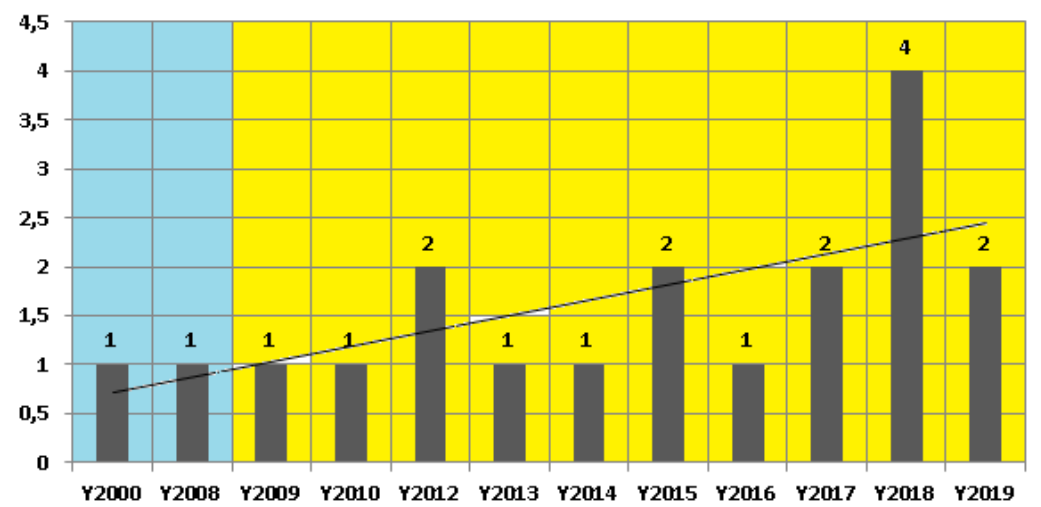

Fig. 1. Distribution of thematic publications on the problems of multilingualism in chronology.

As shown in Figure 1, it is possible, with a certain degree of conventionality, to distinguish two periods of a surge in researchers' interest in this issue, each of which covers one decade. The first period refers to 2000-2009 and is characterized by a weak intensity of research on this issue. In the second decade, there is a significant (more than fourfold) increase in the number of studies, which is characterized by the presence of an upward trend. The distribution of studies by the criterion "country of study in which the authors live" made it possible to establish that their affiliation is different. The studies were carried out by scientists from China, Australia, South Korea, Israel, Russia, and the USA.

Figure 2 provides information on studies that were selected on the basis of the principle of "the number of studies is more than one".
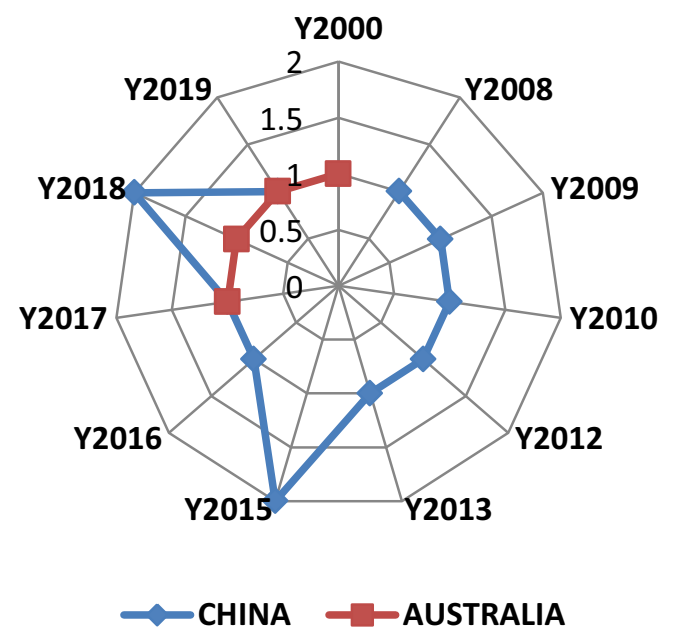

Fig. 2. Distribution of case studies by year of publication

As shown in the Figure 2, the problems of bilingualism are of greatest interest to representatives of multi-ethnic China. Australia is in second place in terms of the intensity of addressing the problems of polylingualism.

The WOS resource contains one publication of scientists from such countries as Russia, the USA, South Korea, Israel. At the same time, the publication activity of the Chinese representatives according to the criterion of their affiliation to the universities of mainland China and special territories, differ significantly. It is shown in Figure 3. 


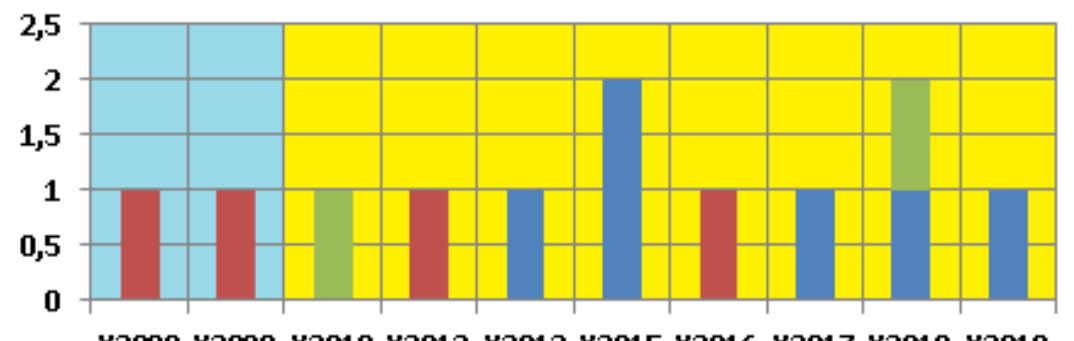

Y2008 Y2009 Y2010 Y2012 Y2013 Y2015 Y2016 Y2017 Y2018 Ү2019

- CHINA HONG KONG INNER MONGOUA

Fig. 3. Distribution of case studies by Chinese authors on polylingualism problems by year of publication

The Figure 3 reflects information that suggests that research at the international level by authors from mainland China appeared much later than research by authors from the autonomous administrative region and the special administrative region. Chronologically, studies by authors from Hong Kong and Inner Mongolia prevail. In these administrative units, the majority of residents, even being ethnic Chinese, do not speak the state Mandarin, but use the Cantonese dialect (Hong Kong) or the languages of 49 national minorities living in Inner Mongolia.

The second stage of the research is devoted to thematic analysis of publications.

Researchers in bilingual language education are addressing issues related to the glycolytic / glycogenetic mechanisms underlying language learning. Woo, J., Kim, J. E., $\mathrm{Im}$, J.J. [6], while studying the role of astrocytes in the plasticity of the brain, established a positive effect of aquaporin-4 (AQP4) on the development of semantic speech fluency.

Researchers identified the most common genetic variant AQP4 (single nucleotide polymorphism rs 162008 with variation $\mathrm{C}$ or $\mathrm{T}$, which has a lower allele frequency of 0.21 ) from a human database $(\mathrm{n}=60706)$ and determined its functionality in modulating AQP4 expression levels in a reporter luciferase assay in vitro.

The first integrative data were obtained to determine the glycogenetic basis, which includes (AQP4) and affects the effectiveness of non-native language learning.

Based on a 15-year experiment in the Inner Mongolia Autonomous Region on the perception by Mongolian bilinguals and Han speakers of Mandarin (official Chinese, Beijing dialect), differences in six pairs of Mandarin (Mandarin) semantic tones (T1-T2, T1-T3, T1- T4, T2-T3, T2-T4, T3-T4), researcher K. Tsukada [7] found the following.

Despite the presence of individual variations, the greatest discrepancies in the accuracy of T2-T3 tone perception were consistently recorded in the Mongolian group. It is suggested that the peculiarities of inadequate perception of these linguistic sematic tones can be overcome as a result of purposeful learning.

Studies by Y. Zheng point to a direct connection between switching between two languages, characteristic of bilinguals, and an increase in the body's cognitive reserve. $\mathrm{Wu}$, Qi; Su, Fengjuan [8]. In a pilot study involving 129 patients diagnosed with probable Alzheimer's disease (of which 48 are Cantonese monolinguals (Cantonese is a dialect common in Hong Kong), 20 Chinese monolinguals, and 61 bilinguals who speak Cantonese and Mandarin), showed that bilinguals have a higher social, professional and intellectual status. Consistent bilingualism delays the onset or slows down of Alzheimer's disease.

Violations of the speech development of children belonging to the bilingual group or who have mastered two dialects at the same time are the focus of Han, Weifeng; Brebner, Chris; McAllister, Sue [9]. 
It has been established that one should be careful to assess the difficulties in the speech development of children of this group, since the morphosyntactic efficiency of speaking in one of the languages may be associated with its insufficient exposure. The authors propose threshold indicators for diagnosing the types and types of disorders.

Studies of the qualitative originality of the linguistic landscape characteristic of Korean schools, in particular, in the Korean Autonomous Prefecture of Yanbian, carried out by Zhang, Zhen'ai; Wen, Liting; Li, Guanghe [10], revealed the dominant influence of the demographic factor, which predetermined the desire of the bilingual population to switch to school teaching within the framework of trilingualism. The concept of double positive transmission of the language is proposed, implying the requirements for the teaching staff, who must speak three languages (Korean, Mandarin, English) and serve as a role model. The presence of motivational factors that determine the positive attitude of the Korean diaspora to the acquisition of knowledge of the Chinese language at a bilingual level is indicated by a study by Gao, Fang \& Park, Jae [11], which proved the orientation of Koreans living in China towards recognizing the need to participate in a "monolingual market economy." The expansion of business contacts with South Korea, according to the findings of F. Gao [11], has determined a new trend towards trilingualism, widely supported by the youth of ethnic diasporas.

A methodological approach to assessing the psycholinguistic pedagogical effect in teaching bilinguals was proposed by Wang, Qian [12], who developed a fuzzy geometric operator (TFEGBM) and a fuzzy weight coefficient (TFWEGBM) based on the Einstein / Bonferroni theories for aggregating fuzzy information about the level of bigingual training. This approach allowed not to consider the subjective opinion of an expert as the only criterion for assessing knowledge of a foreign language.

Research within the framework of the second cluster concerned mainly topical problems of the organization of the educational process within the framework of the implementation of the concept of additive bilingualism, which is characterized by the addition of a second language and culture without replacing or displacing the first.

The largest amount of research is devoted to the design or evaluation of bilingual SinoEnglish programs, which have been actively promoted since 2001.

Teaching in English using quest technology at universities is seen as a reorientation to "flexible bilingualism" (Wang, Weihong; Curdt-Christiansen, Xiao Lan [13], Lin, Xiang [14], $\mathrm{Hu}$ [15]); restrictions on the English language as the state language in the past in Hong Kong due to the active promotion of mandarin (Nikolayev, A., Egorova, M., Barov, S. [16]); experimental introduction of additive bilingualism or trilingualism in schools with a predominance of ethnic minorities (Finifrock, J.E.; Schilken, Doerthe [17]; a survey of specialists participating in additive bilingualism programs.

Within the framework of the third cluster of the study of problems, the research topics are associated with the consideration of language and cultural policy along the line "Han (Chinese) - not Han (not Chinese) language" as a marker of culture. The problematic is considered in the logic of studying the specifics of the influence of foreign languages on children brought up in emigrant, expatriate, transnational and mixed families (Bongsu, Park; Youngsoon, Kim [18]), the spread of language and culture is studied through the Confucius Institutes (Spolsky, B. [19]), development of professional and communicative competencies of Chinese sailors (Fan, L. [20]), support for non-verbal strategies of behavior in culture and everyday life, sign language as a means of understanding Chinese culture (F. Gao [21]).

\section{Conclusion}


In general, we can conclude that research on the problems of polylingualism covers three thematic clusters: 1) problems of bilingual / multilingual language education of representatives of ethnic minorities; 2) the development of additive bilingualism, mainly in the form of Sino-English bilingual education programs; and 3) the study of the culture of regional communities abroad, in growing cities and new autonomous territories. In the Chinese scientific discourse, despite the multifaceted consideration of the aforementioned problems, addressed to the implementation of the State Program for the Implementation of Regional Autonomy of Ethnic Minorities, studies characterizing the fundamental integral problems of polylingualism as a socio-cultural phenomenon are not yet presented at the proper level of coverage. The study of the problems of polylingualism on the example of China is a promising topic, since it will reveal the patterns associated with the psychophysiological, philological, cultural and educational aspects of polylingualism on a significant amount of diversity of material.

\section{References}

1. O. Ryndina, Tomsk state university journal of cultural studies and art history, 35, 264274 (2019) Doi: 10.17223/22220836/35/24

2. X. Gao, Y. Zheng, Journal of multilingual and multicultural development, 40(7) SI, 555-561 (2019) Doi: 10.1080/01434632.2019.1571073

3. H. Wang, X. Chao, S. Sun, Asia pacific journal of education, 40(2), 167-181 (2020) Doi: 10.1080/02188791.2019.1682515

4. O. Fedotova, V. Latun. Mediterranien journal of Social Sciences, 4(6), 356-361 (2015) Doi: 10.5901/mjss.2015.v6n4p356

5. B. Meskhi, S. Ponomareva, O. Fedotova. (ESSD 2019) https://www.atlantispress.com/proceedings/essd-19/125912952 Doi: 10.2991/essd-19.2019.2 (Last accessed 13.07.2020)

6. J. Woo, J. Kim, J. Im. Molecular psychiatry, 23(4), 1021-1030 (2018) Doi: 10.1038/mp.2017.113

7. K. Tsukada, INTERSPEECH-2018. 2539-2543 (2018) Doi: 10.21437/Interspeech.2018-48

8. Y. Zheng, Q. Wu, F. Su, Dementia and geriatric cognitive disorders, 45, 210-219 (2018) Doi: 10.1159/000488485

9. W. Han, Ch. Brebner, S. McAllister, International journal of speech-language pathology, 18(2), 35-146 (2016) Doi: 10.31109/17549507.2015.1081285

10. Z. Zhang, L. Wen, Trilingualism in education in China: models and challenges, 12, 4764 (2015) Doi: 10.1007/978-94-017-9352-0_3

11. F. Gao, J. Park, Journal of multilingual and multicultural development, 33(6), 539552 (2012) Doi: 10.1080/01434632.2012.692683

12. Q. Wang, Journal of intelligent \& fuzzy systems, 32(1), 1139-1146 (2017) Doi: $10.3233 /$ JIFS-16531

13. W. Wang, C.-C. Weihong, X. Lan, International journal of bilingual education and bilingualism, 22(3), 322-337 (2019) Doi: 10.1080/13670050.2018.1526254

14. X. Lin, ICFCA 2010, 73-76 (Nanjing, 2010)

15. G. Hu, Review of educational research, 78(2), 195-231 (2008) Doi: 10/3102/0034654307313406 
https://journals.sagepub.com/doi/full/10.3102/0034654307313406 (Last accessed 13.07.2020)

16. A. Nikolayev, M. Egorova, S. Barov, INTED2019, 7018-7023 (2019) Doi: 10.21125/inted.2019.1699

17. J. Finifrock, D. Schilken. Trilingualism in education in china: Modella and challenges, 12, 199-221 (2015) Doi: 10.1007/978-94-017-9352-0_9

18. B. Park, Y. Kim, Journal of the international network for Korean language and culture, 15(1), 93-120 (2018) Doi: 10.15652/ink.2018.15.1.093

19. B. Spolsky, Language, 90(4), E165-E179 (2014) Doi: 10.1353/lan.2014.0075

20. L. Fan, Transnav-international journal on marine navigation and safety of sea transportation, 11(4), 577-581 (2017) Doi: 10.12716/1001.11.04.01

21. F. Gao, Journal of multilingual and multicultural development, 30(6) (2009) https://www.tandfonline.com/doi/figure/10.1080/01434630903147922?scroll=top\&nee dAccess $=$ true. 525-534 Doi: 10.1080/01434630903147922 (Last accessed 15.07.2020) 